\title{
Tsafon
}

Revue d'études juives du Nord

$74 \mid 2017$

La Déclaration Balfour, vers l'État d'Israël ?

\section{Christian Morzewski (dir.), Korczak, la cause des enfants}

Olivier Rota

\section{(2) OpenEdition}

1 Journals

Édition électronique

URL : https://journals.openedition.org/tsafon/445

DOI : $10.4000 /$ tsafon.445

ISSN : 2609-6420

Éditeur

Association Jean-Marie Delmaire

Édition imprimée

Date de publication : 1 décembre 2017

Pagination : 179-180

ISSN : 1149-6630

\section{Référence électronique}

Olivier Rota, " Christian Morzewski (dir.), Korczak, la cause des enfants », Tsafon [En ligne], 74 | 2017, mis en ligne le 31 mai 2018, consulté le 24 juin 2021. URL : http://journals.openedition.org/tsafon/445 ; DOI : https://doi.org/10.4000/tsafon.445

Ce document a été généré automatiquement le 24 juin 2021.

Tsafon. Revues d'études juives du Nord 


\title{
Christian Morzewski (dir.), Korczak, la cause des enfants
}

\author{
Olivier Rota
}

\section{RÉFÉRENCE}

Christian Morzewski (dir.) : Korczak, la cause des enfants, Arras, Artois Presses Université, Cahiers Robinson $\mathrm{n}^{\circ}$ 42, 2017, 156 p., $16 €$.

1 La dernière livraison des Cahiers Robinson réunit les actes d'un colloque consacré à Janusz Korcazk, tenu à l'Université d'Artois, en coopération avec l'Institut de civilisation et d'études polonaises, les 15 et 16 septembre 2016.

2 De Korczak, on connaît surtout, en France, le roman Le roi Mathias $1^{\text {er }}$. La digne silhouette de l'homme, tenant par la main "ses enfants" jusqu'au camp d'extermination de Treblinka, s'est aussi imposée comme l'une des images les plus terribles du génocide juif. Mais l'imposant travail d'éducateur de Korczak reste encore assez confidentiel, en dépit de la fondation en 1979 de l'Association Française Janusz Korczak (AJFK), et d'une actualité éditoriale qui ne se dément pas, notamment depuis 2010. Autant dire que ce colloque, qui suit les célébrations de l'année 2012, déclarée « Année Korczak » par le Parlement polonais, à l'occasion du $100^{\mathrm{e}}$ anniversaire de la création du premier des deux orphelinats qu'il fonda à Varsovie, et du $70^{\mathrm{e}}$ anniversaire de son assassinat, était particulièrement le bienvenu.

3 Rassemblant neuf contributions, le présent dossier entreprend d'éclairer plusieurs aspects de la genèse et du devenir de l'œuvre de Korczak.

4 Katia Vandenborre ouvre le volume par une présentation de la maison d'édition Mortkowicz; cette célèbre maison d'édition, qui publia Korczak de son vivant, développa autour de Janina Mortkowicz une collection de littérature pour la jeunesse, associant un credo esthétique à des ambitions éducatrices courageuses. Guillemette Tison expose toute l'ambigüité du Roi Mathias : le lectorat que le roman vise, mais aussi son statut de fable politique. Monika Salmon et Magdalena Kicińska s'emploient 
ensemble à sortir de l'ombre "Mademoiselle Stefa»: celle qui travailla comme éducatrice aux côtés de Korczak et joua le rôle ingrat de contrebalancer, par sa fermeté, tout ce que «Le docteur» avait de fantaisiste dans sa relation avec les enfants de l'orphelinat.

5 Éléonore Hamaide-Jager et Béatrice Finet signent chacune une contribution analysant les productions littéraires actuelles présentant le personnage de Korczak aux enfants. Chacune à leur façon, elles soulignent la portée, si ce n'est le projet, inévitablement moral de ces ouvrages, marqués par le destin tragique du vieil éducateur. Parmi les publications étudiées, celle d'Irène Cohen-Janca, Le dernier voyage, bénéfice d'un éclairage particulier, sous la forme d'un entretien de l'auteur avec Myriam White-Le Goff. Zofia Bobowicz, traductrice et directrice de la collection "Janusz Korczak », et Thomas Jallaud, directeur des éditions Fabert, témoignent de leur engagement à faire connaître l'œuvre au public français. Patricia Haluska, présidente de l'AJFK, retrace l'historique et l'activité de son association, ainsi que ses missions: contribuer à la dignité de l'enfant et à son épanouissement.

6 Le dossier se clôt par une lecture magistrale du Journal du ghetto de Korczak par le coordinateur $\mathrm{du}$ volume, Christian Morzewski. Arguant de la fonction fondamentalement réparatrice de l'écriture, C. Morzewski analyse le journal dans lequel Korczak a consigné ses mémoires, mais aussi ses rêves et ses désirs, pendant la terrible année 1942. Rédigé au plein cœur du ghetto de Varsovie, ce journal atteste des efforts du docteur pour garantir un semblant de vie ordinaire à ses enfants; s'il exprime l'extrême pudeur de Korczak face à l'épreuve, il en révèle aussi la dure lucidité.

7 Le volume réussit à restituer les enjeux d'une réception littéraire de l'œuvre de Korczak. Sa valeur, qui repose autant sur les analyses produites que sur les témoignages réunis, démontre, s'il en faut, toute la nécessité de mieux faire connaître du public français l'œuvre du « Vieux docteur ». 